\title{
Transient effects of tendon disconnection on the survivability of a TLP in moderate-strength hurricane conditions
}

\author{
Moo Hyun Kim and Zhi Zhang
}

Dept. of Civil Engineering (Ocean Engineering Program), Texas A\&M University College Station, TX 77843, USA

\begin{abstract}
The primary objective of this paper is to investigate the dynamic stability and survivability of a four-column classic TLP (tension-leg platform) under less-than-extreme storm conditions where one or more tendons have been lost due to damage or disconnect. The transient responses of the platform and tendon tensions at the moment of disconnection are particularly underscored. The numerical simulation is based on the BE-FE hybrid hull-tendon-riser coupled dynamic analysis in time domain. Compared to the common industry practice of checking the system without a failed tendon in the beginning, the maximum tension on the neighboring tendon can be significantly increased at the moment of disconnection due to the snap-like transient effects, which can lead to unexpected failure of the total system. It is also found that the transient effects can be reduced with the presence of TTRs (top-tensioned risers) with pneumatic tensioners. It is also seen that the TLP cannot survive in the 100-yr hurricane condition after losing one tendon.
\end{abstract}

KEYWORDS: TLP tendon disconnection; Transient effects; Hull-tendon-riser coupled dynamic analysis; Dynamic survivability in moderate strength hurricanes; Comparison with common industry practice

\section{INTRODUCTION}

One of the main advantages of the TLP concept is its minimal responses and inherent stability, primarily in the vertical modes (heave, pitch and roll), which makes it most suitable for supporting vertical top-tensioned risers with dry trees, as well as for supporting steel catenary risers to tie in subsea flow lines and export pipelines. The TLPs use vertical mooring system called 'tendons' to be very stiff for vertical plane motions and soft for horizontal-plane motions. Therefore, the natural frequencies of all the 6DOF motions are located outside the bandwidth of incident wave energy. The early TLP designs for major hub developments consisted of four columns connected by a ring pontoon at the base and supporting the outer corners of a rectangular deck at the top. Attached to each column was a minimum of three tendons. Later TLP designs for marginal fields and smaller topsides payloads required less hull buoyancy and less total tendon pretension. Similar intact stability as for the early TLP designs was achieved with more efficient distribution of buoyancy and relatively larger tendon footprints (e.g. Yang et al., 2008), but also with fewer tendons per corner.

The current practice for design of TLPs for the Gulf of Mexico, as documented in the API Recommended Practice for Design of Tension Leg Platforms (API-RP 2T), does not distinguish between the various classes of TLPs under the

Corresponding author: M. H. Kim

e-mail:m-kim3@tamu.edu assumption that all design analysis procedures and safety factors are equally applicable to all concepts. Questions have been raised as to whether the design practice should recognize what appear to be inherently different levels of stability and survivability for damaged tendon conditions among the various classes of TLPs. The underlying concern is whether the design practice ensures that all classes of TLPs will be designed with adequate robustness to guard against total loss of the platform in the unlikely event of tendon failure due to whatever reason. As an illustration, the dynamic survivability of a classic four-column TLP after the loss of one or two tendons in a 10-year hurricane environment is simulated and analyzed under the assumption that the incident waves, winds, and currents are collinear.

The analysis of TLP platform response under damaged tendon conditions is in general not so easy. This is in part because of the large number of possible damage scenarios, including effects of inter-dependent progressive component failures. Another major source of difficulty lies in the modeling of highly nonlinear and transient phenomena typically in play during progressive failure situations. As the platform loses tendon restraints and progressively heels over, various nonlinear phenomena, such as variable areas exposed to wind and wave loading, variable wet volume and the corresponding change in hydrodynamic coefficients, large platform yaw rotations etc., need to be included. Because of these difficulties, it is not common for TLP designers to perform rigorous dynamic simulations of the total loss of tendons in extreme (100-year return period and beyond) 
environmental conditions. On the other hand, the survivability of the platform in a moderate strength hurricane with the loss of one or two tendons is still of great practical importance. In checking the case, designers remove one tendon in the beginning and run simulations. Therefore, the transient effects at the moment of disconnection are missing. To the best of authors' knowledge, we are not aware of any prior publications (except our previous work published in a conference proceeding; Yang et al., 2008) in the public domain that have addressed dynamic survivability of TLPs with damaged tendons including transient effects. In this case, until all the tendons at one corner are totally lost, the change of heel angles and wet volumes are relatively minor and their effects can be neglected, which is assumed in the present analysis.

During the past decade, a reliable time-domain vesselmooring-riser coupled dynamic analysis program has been developed for multi-floating systems (e.g. Ran \& Kim, 1997; Kim et al., 2001) and it is applied to the present application. The hull hydrodynamic coefficients are calculated from the 3D diffraction/radiation panel program WAMIT (Lee et al., 1991). The tendon and riser dynamics are calculated by using the FE of rod equation (Garrett, 1982). The coupled hull and line dynamics are solved simultaneously in a combined matrix at every time step. The importance of the hullmooring-riser coupled dynamic analysis for deepwater applications is well addressed in Ma et al. (2000) and Wichers et al. (2004).

Table 1 TLP Hull parameters.

\begin{tabular}{|c|c|}
\hline Description & Magnitude \\
\hline Draft $(f t)$ & 80.0 \\
\hline Total Weight $($ kips $)$ & 50,558 \\
\hline Total Tendon Pretension at the Top $(k i p s)$ & 15,520 \\
\hline Total Riser Pretension at the Top $(k i p s)$ & 4,348 \\
\hline Displacements $($ kips $)$ & 70,426 \\
\hline Vertical Center of Gravity from MWL $(f t)$ & 28.1 \\
\hline Vertical Center of Buoyancy from MWL $(f t)$ & -49.8 \\
\hline Roll Radius of Gyration $(f t)$ & 108.9 \\
\hline Pitch Radius of Gyration $(f t)$ & 108.9 \\
\hline Yaw Radius of Gyration $(f t)$ & 106.3 \\
\hline Wind Load Coefficient $\left(k i p s /(f t / s e c)^{2}\right)$ & 0.0665 \\
\hline Center of Pressure from MWL $(f t)$ & 125.0 \\
\hline Column diameter/draft $(f t)$ & $54(16 m) / 80(24 m)$ \\
\hline Pontoon height/width $(f t)$ & $24(7 m) / 27(8 m)$ \\
\hline Column center-to-center spacing $(f t)$ & $(61 m)$ \\
\hline
\end{tabular}

\section{TLP SYSTEM AND ENVIRONMENTS}

In this study, a conventional 4-column TLP (Tension Leg Platform) with rectangular pontoons is chosen to perform the Hull/Tendon/Riser couples dynamic analysis. The hull parameters of the target TLP are listed in Table 1.

The target TLP has 8 tendons, as numbered in Fig.1, two on the outermost part of each column. There are also 8 toptensioned risers, as shown in Fig. 1, including one drilling riser and seven production risers. In the numerical simulation, each tendon and riser is divided into 25 high-order FE elements. The properties of the tendons and risers are listed in Table 2.
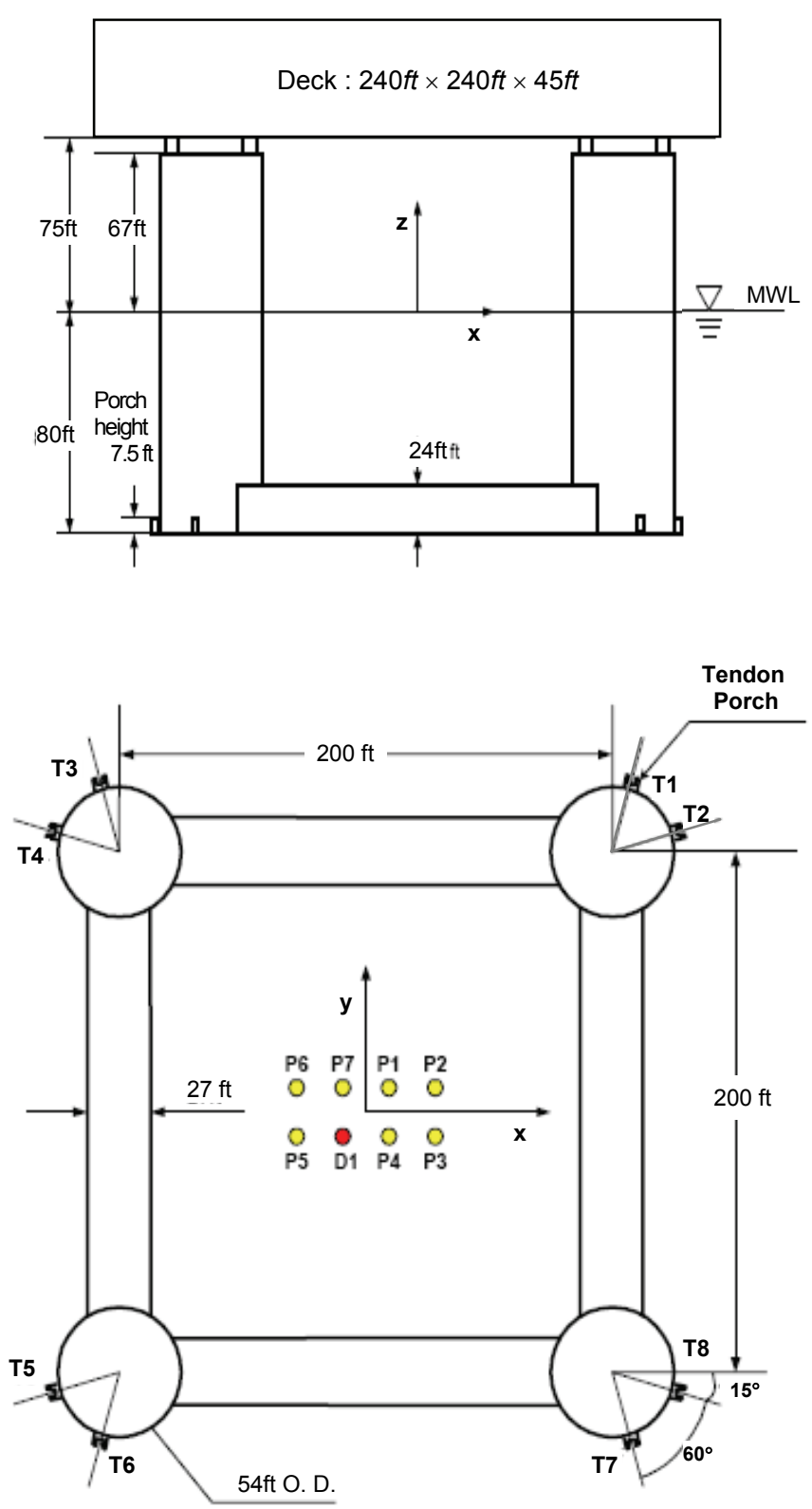

Fig. 1 TLP hull, tendons, and risers layout. 
Table 2 Material properties of the tendons and risers.

\begin{tabular}{|c|c|c|c|}
\hline & Tendons & Drilling Riser & Production Risers \\
\hline Wet Weight & $\begin{array}{c}68.98 \mathrm{lb} / \mathrm{ft} \\
(102.65 \mathrm{~kg} / \mathrm{m})\end{array}$ & $\begin{array}{c}173.68 \mathrm{lb} / \mathrm{ft} \\
(258.86 \mathrm{~kg} / \mathrm{m})\end{array}$ & $\begin{array}{c}115.41 \mathrm{lb} / \mathrm{ft} \\
(172.24 \mathrm{~kg} / \mathrm{m})\end{array}$ \\
\hline Dry Weight & $\begin{array}{c}425.66 \mathrm{lb} / \mathrm{ft} \\
(634.84 \mathrm{~kg} / \mathrm{m})\end{array}$ & $\begin{array}{c}327.3 \mathrm{lb} / \mathrm{ft} \\
(488.19 \mathrm{~kg} / \mathrm{m})\end{array}$ & $\begin{array}{c}157.56 \mathrm{lb} / \mathrm{ft} \\
(234.91 \mathrm{~kg} / \mathrm{m})\end{array}$ \\
\hline Diameter & $\begin{array}{l}2.67 \mathrm{ft} \\
(0.81 \mathrm{~m})\end{array}$ & $\begin{array}{l}1.75 \mathrm{ft} \\
(0.53 \mathrm{~m})\end{array}$ & $\begin{array}{c}0.92 \mathrm{ft} \\
(0.28 \mathrm{~m})\end{array}$ \\
\hline EA & $\begin{array}{l}3.76 \times 10^{6} \mathrm{kips} \\
\left(1.67 \times 10^{7} \mathrm{KN}\right) \\
\end{array}$ & $\begin{array}{c}2.21 \times 10^{6} \mathrm{kips} \\
\left(9.83 \times 10^{6} \mathrm{KN}\right) \\
\end{array}$ & $\begin{array}{l}9.75 \times 10^{6} \mathrm{kips} \\
\left(4.34 \times 10^{6} \mathrm{KN}\right) \\
\end{array}$ \\
\hline $\begin{array}{c}\text { EI } \\
\left(k i p s * f t^{2}\right)\end{array}$ & $\begin{array}{c}3.08 \times 10^{6} k i p s^{*} f t^{2} \\
\left(1.27 \times 10^{6} N^{*} m^{2}\right)\end{array}$ & $\begin{array}{c}0.00 \text { kips }^{*} f t^{2} \\
\left(0.00 \mathrm{KN}^{*} \mathrm{~m}^{2}\right)\end{array}$ & $\begin{array}{c}0.00 k i p s^{*} f t^{2} \\
\left(0.00 K N^{*} m^{2}\right)\end{array}$ \\
\hline $\begin{array}{c}\text { Inertial } \\
\text { Coefficient }\end{array}$ & 2 & 2 & 2 \\
\hline Drag Coefficient & 1 & 1 & 1 \\
\hline $\begin{array}{c}\text { Top } \\
\text { Pre-tension }\end{array}$ & $\begin{array}{c}1.94 \times 10^{3} \text { kips } \\
\left(8.63 \times 10^{3} \mathrm{KN}\right)\end{array}$ & $\begin{array}{c}7.29 \times 10^{2} \mathrm{kips} \\
\left(3.24 \times 10^{3} \mathrm{KN}\right)\end{array}$ & $\begin{array}{c}5.17 \times 10^{2} \mathrm{kips} \\
\left(2.30 \times 10^{3} \mathrm{KN}\right)\end{array}$ \\
\hline Break Strength & $\begin{array}{c}7.59 \times 10^{3} \mathrm{kips} \\
\left(3.38 \times 10^{4} \mathrm{KN}\right)\end{array}$ & $\begin{array}{c}2.85 \times 10^{3} \mathrm{kips} \\
\left(1.27 \times 10^{4} \mathrm{KN}\right)\end{array}$ & $\begin{array}{c}2.02 \times 10^{3} \mathrm{kips} \\
\left(8.99 \times 10^{3} \mathrm{KN}\right)\end{array}$ \\
\hline
\end{tabular}

The TTRs (top-tensioned risers) are connected to the onboard dry-tree facilities by a flexible pneumatic tensioner, the numerical model of which is given, for example, in Yang et al. (2007). The relation between the tension $T$ and the stroke $z$ of the tensioner is given by $T=T_{0} /\left(1+z / z_{0}\right)^{n}$, where $z_{0}=$ effective length of gas in the associated accumulator, $T_{0}$ $=$ initial top tension at stroke $\mathrm{z}=0$, and $n=$ gas constant.

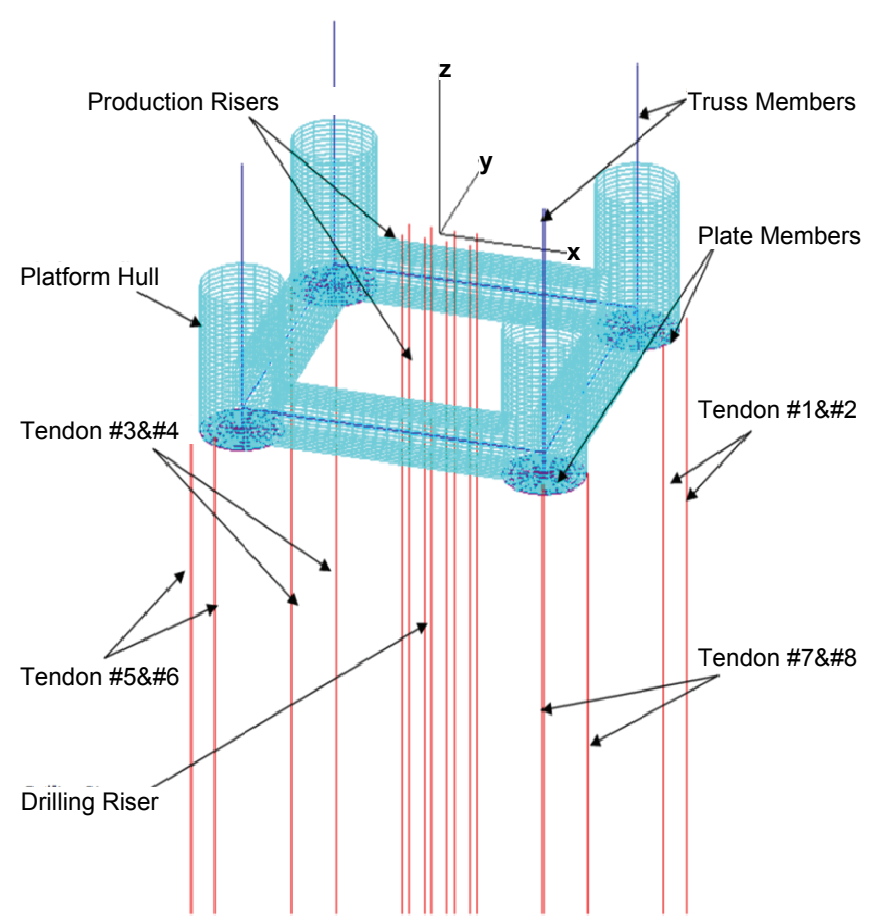

Fig. 2 TLP Numerical model.
The water depth is $3000 \mathrm{ft}$ and the total mass of the platform hull is $1.57 \times 10^{6} \mathrm{lb}(712,800 \mathrm{~kg})$. A total of 1420 panel elements for a quarter of the platform hull are used in the hydrodynamic computation. The damping of the platform hull is modeled by using 4 equivalent plate members and 4 truss members. The viscous forces and the damping on the respective hull elements including the effects of free-surface fluctuations are calculated through the modified Morison's formula

The panel model of the platform hull and the mooring/riser arrangement are shown in Fig. 2. The secondorder sum-frequency wave excitations are not included since they are not considered to be important for the present analysis. However, the second-order slowly varying wave excitations are included through the so-called Newman's approximation method.

The time-domain simulations were carried out in the ranges of $2500 \sim 5000$ seconds. The time step is set to be 0.05 seconds. To suppress the start-up transient responses as much as possible, the environmental force was gradually applied from zero to the actual value during the ramping period of 250 seconds.

Two environmental conditions with collinear wind, wave, and current considered here, are the API 10-year and 100year hurricane condition in the GOM (Gulf of Mexico) (see Table 3 and 4). JONSWAP wave spectra are used for irregular-wave generation and API spectra are used for dynamic wind-velocity generation. A steady shear current with piecewise-linear decay rates is imposed. Two different incident angles ( 0 degree and 45 degree) are chosen to see the effects of environmental heading angles. Since the TLP was designed to survive for 10-year storm with the loss of one tendon, the weather-side (taut-side) tendon \#5 was intentionally forced to break at the bottom porch during the simulation to observe the subsequent behaviors of the 
platform including transient effects at the moment of disconnection. The breaking time is set when a peak of high waves reaches the instantaneous position of the TLP. After disconnection, the failed tendon is still attached to the hull free-hanging. However, in the 100-year condition, the TLP is not supposed to survive after losing one tendon, which will be shown in the next section.

Table 3 Wave and wind conditions.

\begin{tabular}{|c|c|c|}
\hline & $10-\mathrm{yr}$ & $100-y r$ \\
\hline Significant Wave Height & $\begin{array}{l}31.8 \mathrm{ft} \\
(9.7 \mathrm{~m})\end{array}$ & $\begin{array}{c}51.8 f t \\
(15.8 \mathrm{~m})\end{array}$ \\
\hline Wave Peak Period & $12.7 \mathrm{sec}$ & $15.4 \mathrm{sec}$ \\
\hline Enhancement Parameter ( $\tilde{a})$ & 2.4 & 2.4 \\
\hline $\begin{array}{c}\text { One Hour Mean Wind } \\
\text { Velocity at } 10 m \text { Elevation }\end{array}$ & $\begin{array}{l}86.0 \mathrm{ft} / \mathrm{sec} \\
(26.2 \mathrm{~m} / \mathrm{sec})\end{array}$ & $\begin{array}{l}144.8 \mathrm{ft} / \mathrm{sec} \\
(44.1 \mathrm{~m} / \mathrm{sec})\end{array}$ \\
\hline Current Surface Velocity & $\begin{array}{l}7.9 \mathrm{ft} / \mathrm{sec} \\
(2.4 \mathrm{~m} / \mathrm{sec})\end{array}$ & \\
\hline
\end{tabular}

Table 4 Current conditions in both 10 years condition and 100 years condition.

\begin{tabular}{|c|c|}
\hline Depth & Current Velocity \\
\hline Surface & $7.9 \mathrm{ft} / \mathrm{sec}(2.4 \mathrm{~m} / \mathrm{sec})$ \\
\hline$-165.5 \mathrm{ft}(-50.4 \mathrm{~m})$ & $5.9 \mathrm{ft} / \mathrm{sec}(1.8 \mathrm{~m} / \mathrm{sec})$ \\
\hline$-331.0 \mathrm{ft}(-100.9 \mathrm{~m})$ & $0.0 \mathrm{ft} / \mathrm{sec}(0.0 \mathrm{~m} / \mathrm{sec})$ \\
\hline$-1000 \mathrm{ft}(-3048.0 \mathrm{~m})$ & $0.0 \mathrm{ft} / \mathrm{sec}(0.0 \mathrm{~m} / \mathrm{sec})$ \\
\hline
\end{tabular}

\section{NUMERICAL RESULTS AND DISCUSSIONS}

When a tendon is removed from the system (either due to defect in fabrication, damage during tow, crack development during service or accidental unlatch from bottom porch), the burden of extra buoyancy and stabilizing righting moments is transferred to and redistributed among the remaining tendons. To investigate the survivability of the TLP under the tendondamaged condition in a moderate-strength hurricane, we intentionally disconnect the taut-side tendon $\# 5$ at a specific time when a high wave peak reaches the instantaneous position of the TLP $(462.5 s)$ and continued to carry out the simulation until $2500 \mathrm{~s}$. It is assumed that the disconnection happens at the bottom porch.

We first consider the case of 10-year hurricane in which the TLP is supposed to survive after the loss of one tendon. The supposed worst heading, 45 degrees, is selected first. The simulated 6-DOF motions are presented in Fig. 3.
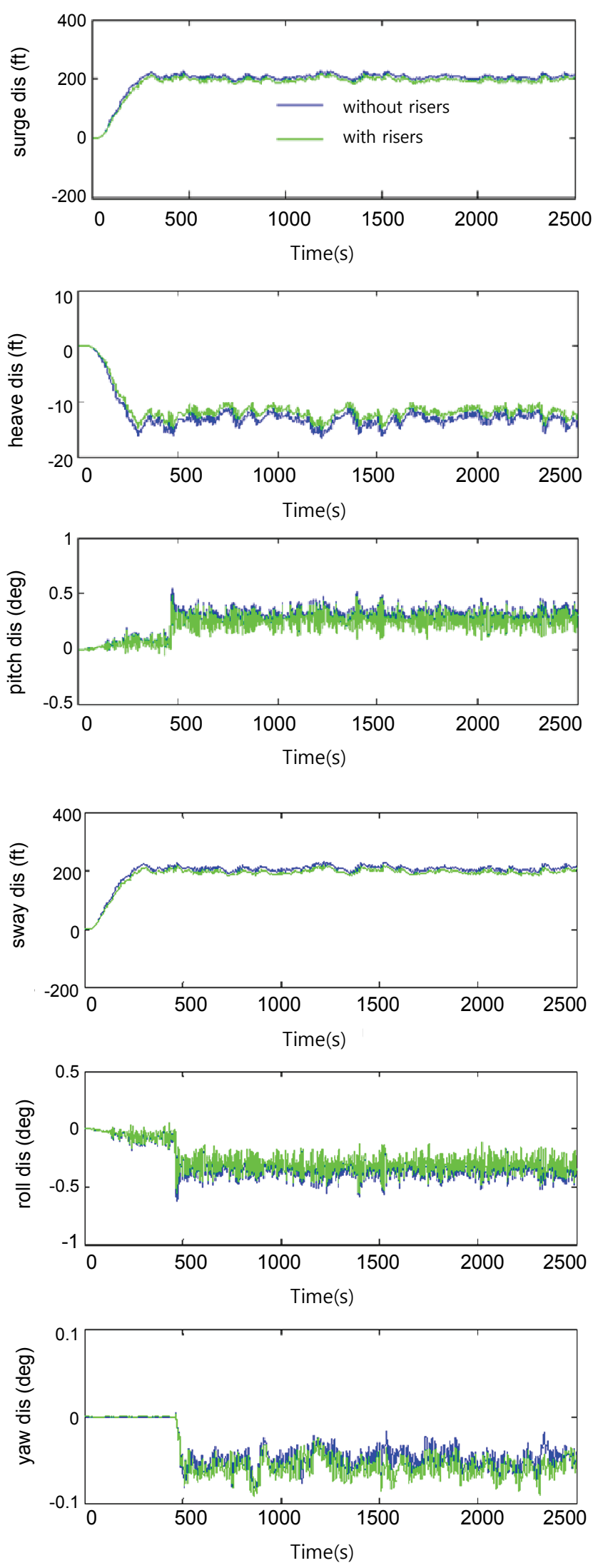

Fig. 3 TLP-motion time series comparison, model without and with risers API 10 year's condition, $45^{\circ}$ incident angle, tendon \#5 forced to break at $462.5 \mathrm{sec}$. 

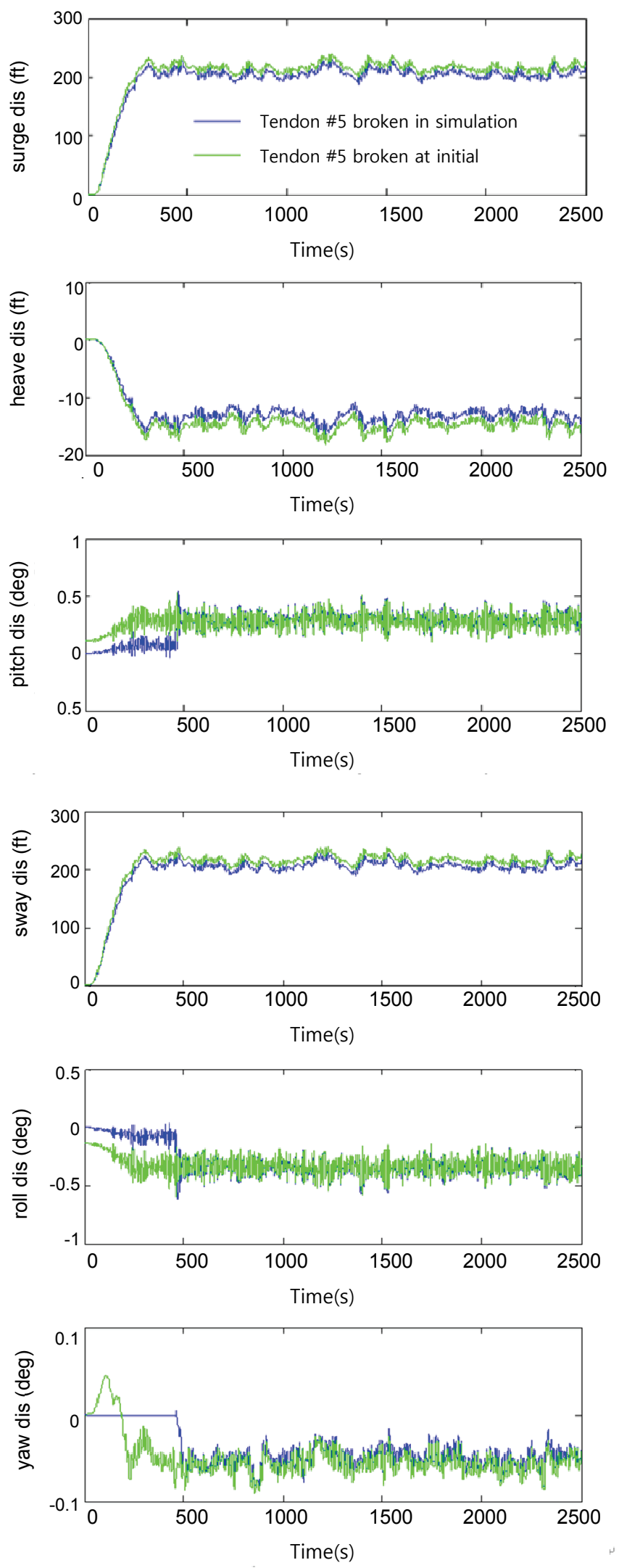

Fig. 4 TLP-motion time series comparison, tendon \#5 broken during and before simulation, API 10 year's condition, $45^{\circ}$ incident angle, tendon \#5 forced to break at $462.5 \mathrm{sec}$.
In the horizontal plane, the TLP experiences a large offset, which results in about 14-ft $(4 \mathrm{~m})$ set down in heave. Immediately after the taut-side tendon is lost, the maximum pitch-roll (about 0.5-0.6 degrees) occurs in a very short time interval due to transient effects, which will in turn influence tendon tension. We compared the cases with risers and without risers to see the effects of the riser system on TLP's survivability and transient responses. The differences in hull motions are in general small except the narrow transient region in pitch/roll, where the risers tend to reduce the transient overshoot. As expected, the TLP system becomes a little stiffer both in horizontal and vertical directions with the top-tensioned risers.

In the next figure, Fig. 4, we compared two different cases in which tendon $\# 5$ is disconnected in the beginning and during simulation (at $462.5 \mathrm{sec}$ ), respectively. In both cases, risers are not included. The common industry practice when checking the survivability with the loss of one tendon is running the dynamic simulation without including the tendon in the beginning, which can also be treated by frequencydomain analysis. In this approach, however, the transient effects at the moment of disconnection are not included and the resulting maximum tendon-tension may be underpredicted. Fig. 4 shows that the rotational motions of the two cases are almost identical after the loss of tendon except near the disconnecting time, where the transient overshoot occurs.

\section{Top tension $(/ b)$}
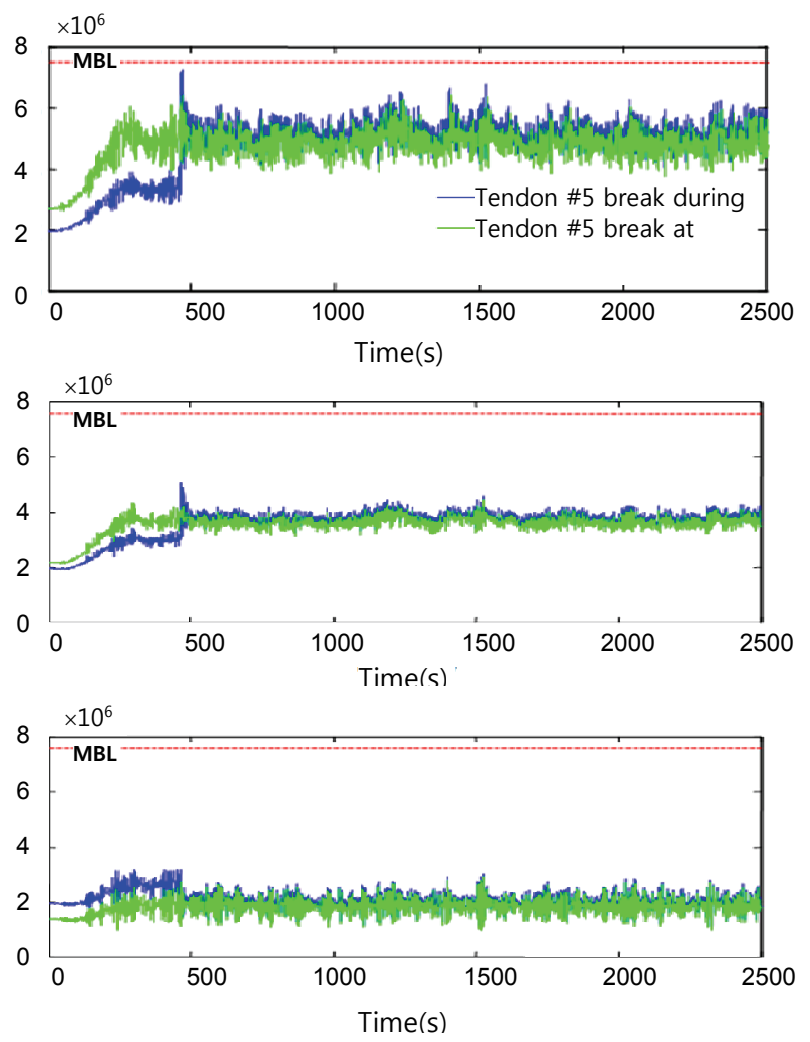

Fig. 5 Top Tension time series comparison with and without transient effects, API 10 year's condition, $45^{\circ}$ incident angle, (model without risers). 
The corresponding time histories of tensions for both cases on tendon \#6(taut-side), \#4(lateral), and \#2(lee-side) are also given in Fig.5. After the loss of one tendon, the mean tension on the remaining tendons is suddenly increased to counterbalance the total net buoyancy. The mean tension of the leeside tendon is, however, decreased due to the heel angle after damage. We can also see the pronounced increase of maximum tension on the neighbouring \#6 tendon at the moment of disconnection due to snap-like transient effects (Maximum tension at the top node equals to $7.22 \times 10^{6} \mathrm{lb}$ with transient effects and $6.52 \times 10^{6} \mathrm{lb}$ without transient effects). If the tendon is to break at the $90 \%$ of MBL, which is actually so in many real cases, the \#6 tendon also fails due to the transient effects, which cannot be detected by the alternative approach without the transient overshoot. When compared with the tension on \#4-tendon, it is seen that the transient effects are the most important to the neighbouring tendons. It is interesting that the tension on the lee-side tendon (\#2) can suddenly decrease due to the sudden downward pitch-roll angles (see Fig.3) that may cause unwanted transient compression(or buckling) loading there.

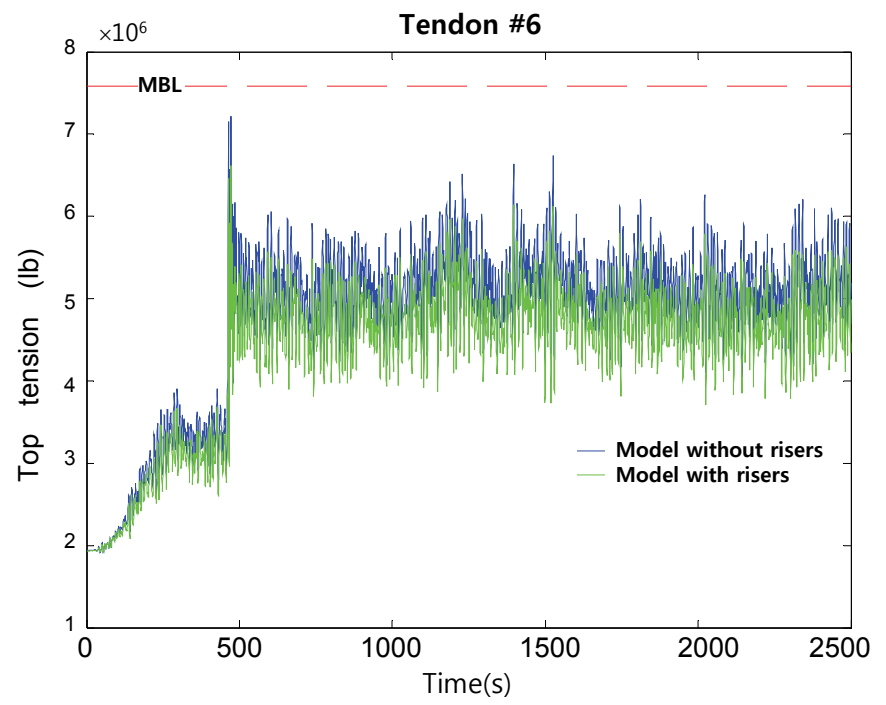

Fig. 6 Tendons' top tension time series comparison between models without and with risers, API 10-year condition, $45^{\circ}$ incident angle, tendon \#5 forced to break at $462.5 \mathrm{sec}$.

Fig. 6 shows the comparison of maximum transient tension on the adjacent \#6-tendon with and without risers. (Maximum tension at the top node equals to $7.22 \times 10^{6} \mathrm{lb}$ without risers and $6.62 \times 10^{6} \mathrm{lb}$ with risers). It is seen that the risers, by adding additional stiffness and resistance, tend to reduce the maximum transient tension, so help the survivability of the system by sharing the burden. Fig. 7 shows the time history of \#6-production-riser tension. The maximum top tension of the risers reached $7.39 \times 10^{5} \mathrm{lb}$ due to the same transient effects. The present pneumatic tensioners function positively to reduce the sudden increase of tendontension.

Fig. 8 shows the tension of the neighboring \#6-tendon and sideway \#4-tendon under the same \#5-tendon-loss scenario but the environment is changed to 100 -year condition.
It is seen that the neighboring tendon also breaks immediately after the disconnection and the burden is transferred to the remaining tendons to progressively fail. It needs to be reminded that the TLP is not so designed as to survive in the 100-year condition after the loss of one tendon. It is also found from our simulation that after losing two tendons in the taut-side corner, the pitch/roll angles are suddenly increased to $25^{\circ}$, so there should be sudden change in wind, wave, and current loadings and hydrodynamic coefficients after that. Therefore, a special care is needed to continue the simulation.

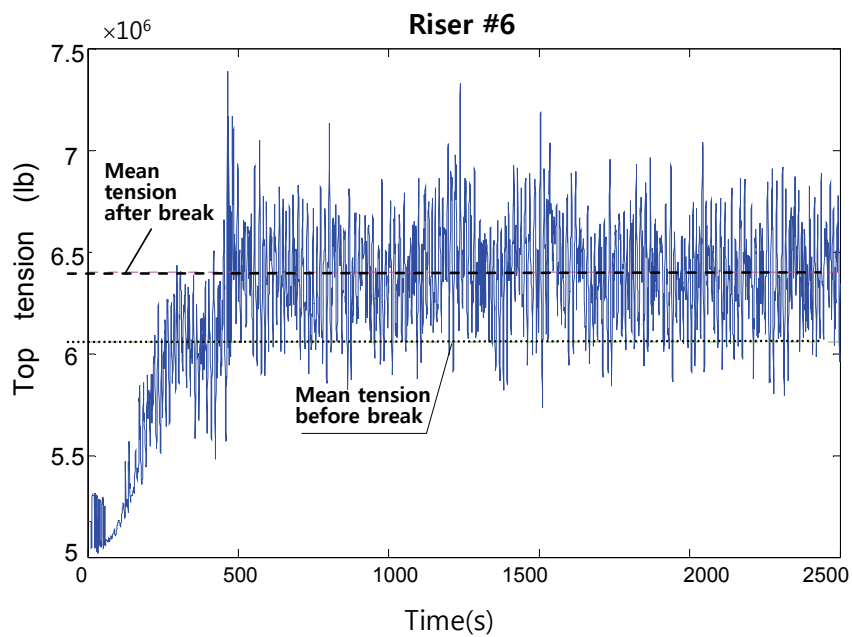

Fig. 7 \#6 Risers' top tension time series, API-10 year condition, $45^{\circ}$ incident angle, tendon $\# 5$ forced to break at $462.5 \mathrm{sec}$ (model with risers).
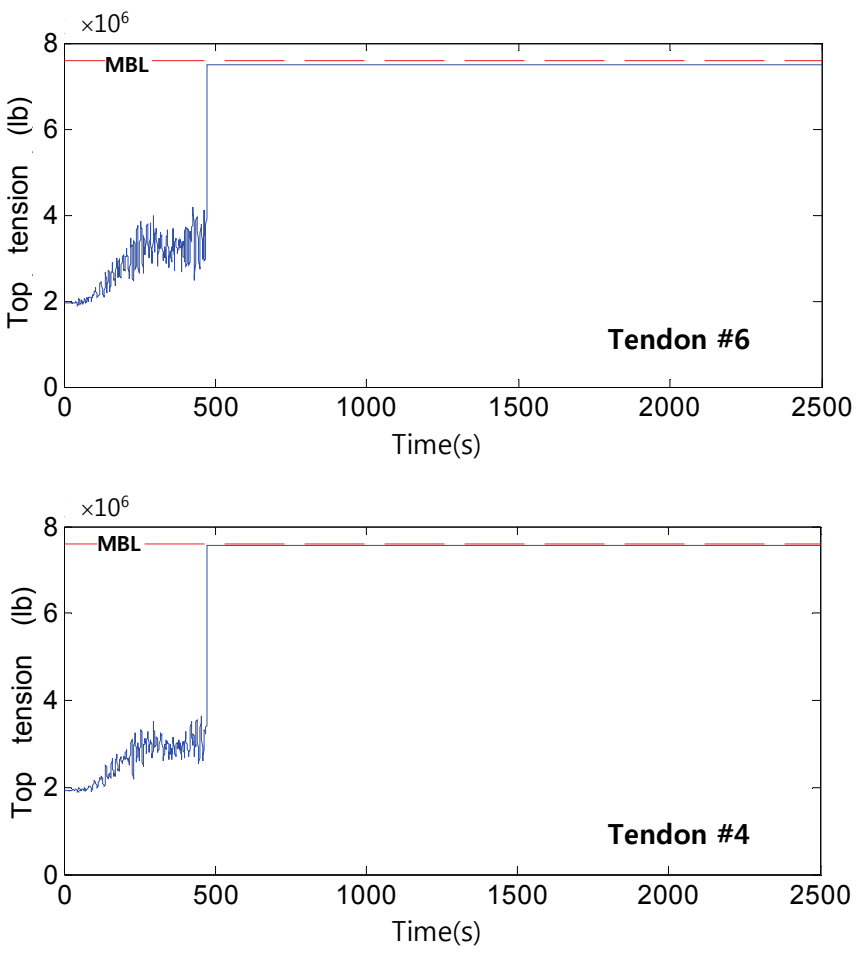

Fig. 8 Top-tension time series, model without risers, API 100-year condition, $45^{\circ}$ incident angle, tendon \#5 forced to break at $473.0 \mathrm{sec}$. 
So far the environmental heading has been fixed at 45 degrees, which is supposed to be the worst case. Fig. 9 shows the tension time history of the \#6-tendon after the loss of \#5tendon in 10-year hurricane condition with $0^{\circ}$ heading. In this case (without risers), the taut-side tendons are four instead of two. Therefore, the transferred burden is relatively less compared to the $45^{\circ}$ heading case (see Fig.5). The maximum tension on the neighboring tendon in this case is $6.86 \times 10^{6} \mathrm{lb}$ compared to $7.22 \times 10^{6} \mathrm{lb}$ in $45^{\circ}$ case.

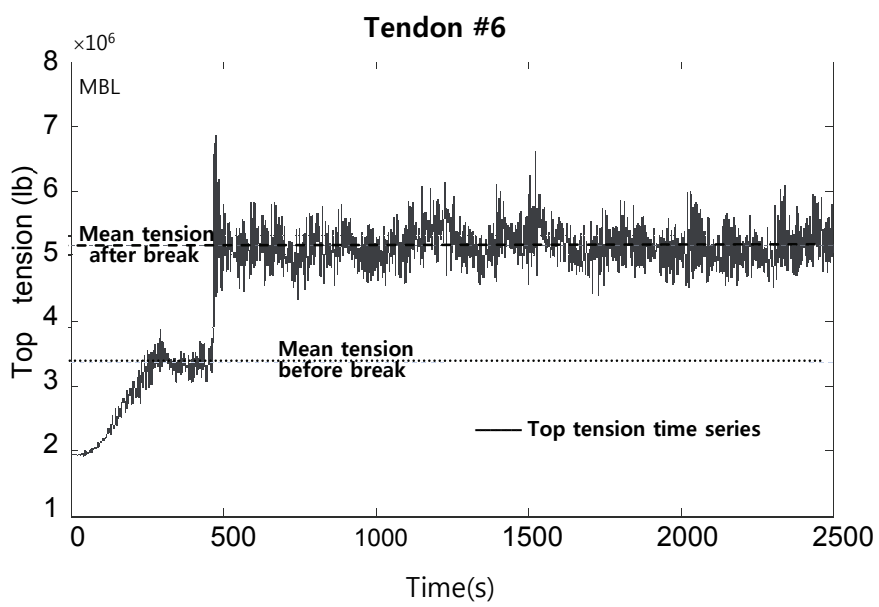

Fig. 9 Top-tension time series, API 10-year condition, $0^{\circ}$ incident angle, tendon \#5 forced to break at $462.5 \mathrm{sec}$.

\section{CONCLUDING REMARKS}

The dynamic stability and survivability of a four-column classic TLP(tension-leg platform) after the loss of one tendon in moderate-strength collinear hurricane conditions (unidirectional irregular waves, dynamic winds and steady shear currents) is investigated by using the hull-tendon-riser coupled dynamic analysis program in time domain. The hull hydrodynamics are solved by BE (Boundary Element) method and the line dynamics are solved by FE method. The hull motions and line dynamics are solved simultaneously as an integrated system in a combined matrix at each time step. The transient responses of the platform and the corresponding tendon tensions at the moment of disconnection are particularly underscored. Compared to the common industry practice i.e. simulation without a failed tendon in the beginning, the maximum tension on a tendon can be significantly increased when the neighboring tendon breaks due to the snap-like transient effects, which can lead to unexpected failure of the total system. Therefore, the inclusion of the transient-overshoot effects in tendon tension is important when checking the survivability of a TLP system in less-than-extreme environmental conditions. It is also found that the transient effects can be reduced with the presence of TTRs (top-tensioned risers) since the pneumatic tensioners provide additional resistance and stiffness. The 45degree incident angle is found to be worse for survivability than 0 -degree heading. It is also seen that the TLP cannot survive in the 100-year hurricane condition after losing one tendon since the transferred burden is too much for the remaining tendons under the extreme condition. After losing all tendons at one corner, the heel angle can be large, and the subsequent dynamic analysis should include such highly nonlinear effects when necessary.

\section{ACKNOWLEDGEMENT}

This research was financially supported by MMS (Minerals Management Service) and the funding is greatly appreciated.

\section{REFERENCE}

API, 2007a. Planning, designing, and constructing tension leg platforms. Draft RP2T, Rev.3.

API, 2007b. Interim guidance on hurricane conditions in the Gulf of Mexico. Bulletin, 2INT-MET.

Garrett, D.L. 1982. Dynamic analysis of slender rods. $J$ Energy Res Technology, 104, pp.302-307.

Kim, M.H. Tahar, A. and Kim, Y.B., 2001. Variability of TLP motion analysis against various design methodologies /parameters. Proc. Int. Offshore

Kim, M.H. and Yue, D.K.P., 1991. Sum- and differencefrequency wave loads on a body in uni-directional Gaussian seas. Journal of Ship Research, 35, pp.127-140

Lee, C.H. Newman, J.N. Kim, M.H. and Yue, D.K.P., 1991. The computation of second-order wave loads. Proc. $10^{\text {th }}$ Offshore Mechanics and Artic Eng. Conference, Stavanger, Norway

Ma, W., Lee, M.Y., Zou, J., and Huang, E., 2000. Deepwater nonlinear coupled analysis tool. Proc. OTC \#12085.

Ran, Z. Kim, M.H., 1997. Nonliear coupled analysis of a tethered spar in waves. Journal of Offsore \& Polar Eng. $7(2)$, pp.111-118.

Wichers, J. and Devlin, P.V. 2004. Benchmark model tests on the deepstar theme structures FPSO, spar, and TLP. OTC \#16582.

Yang, Chan K. Tahar, Arcandra and Kim, M.H. 2007. Linear and nonlinear approach of hydro-pneumatic tensioner modelling for spar global performance. Proceedings of OMAE '07, 10-15 June 2007, San Diego, USA.

Yang, Chan K. Padmanabhan, B. Murray, J. and Kim, M.H., 2008. Transient effect of tendon disconnection on the global motion of ETLP. Proceedings of $27^{\text {th }}$ International Conference on OMAE, 15-20 June 2008, Estoril, Portugal. 